\title{
Differential effects of fluid deprivation on the acquisition and extinction phases of a conditioned taste aversion
}

\author{
CORD B. SENGSTAKE and KATHLEEN C. CHAMBERS \\ Portland State University, Portland, Oregon 97207
}

\begin{abstract}
Previous work has shown that the rate of extinction of a conditioned taste aversion by a male (but not a female) rat is affected by the state of fluid deprivation. In the present study, adult male rats were either fluid deprived or nondeprived during acquisition of the conditioned taste aversion and then either fluid deprived or nondeprived during its extinction. The males that were fluid deprived during extinction showed a faster, female-like rate of extinction regardless of the deprivation state during acquisition. These results were related to previous work showing that the rate of extinction of a conditioned taste aversion is dependent on levels of testosterone.
\end{abstract}

Chambers and Sengstake (1976) have found that males extinguish a conditioned taste aversion more slowly than females. This sexual dimorphism has been shown to be concurrently dependent on testosterone (Chambers, 1976). When males are castrated, they exhibit a fast, female-like rate of extinction. When females and castrated males are given testosterone supplements, they exhibit a slow, male-like rate of extinction. Thus, testosterone increases the length of time the animal takes to extinguish the aversion. If testosterone is not present, the expression of the slower rate of extinction is blocked and the males act like females.

The sexual dimorphism is also blocked when rats are fluid deprived. The rate of extinction seen in females is unaffected by fluid deprivation, but the males, which normally show the slower rate of extinction, will change to the faster, female-like rate if they are fluid deprived. This increased rate of extinction in the deprived male is not due to forced drinking of the conditioned substance, since water was also available during behavioral testing (Sengstake, Chambers, \& Thrower, 1978).

The behavioral similarity between castrated males and fluid-deprived males earlier led us to hypothesize that the effects of fluid deprivation on the rate of extinction occur through a testosterone-dependent mechanism, a hypothesis that was supported by the demonstration that injections of testosterone propionate blocked the effects of fluid deprivation on the rate of extinction in the male rat (Sengstake et al., 1978).

A change in the rate of extinction can be a function of events occurring during the acquisition of the aversion or events occurring during the extinction of the aversion.

We would like to express our thanks to Diana Hainline for her technical assistance during the collection of these data. Requests for reprints may be addressed to the authors at Department of Psychology, Portland State University, P.O. Box 751, Portland, Oregon 97207.
Chambers and Sengstake (1979) have shown that testosterone slows the rate of extinction by altering the extinction (but not the acquisition) process in some unspecified way. The slower rate of extinction of the conditioned taste aversion; the presence, or absence, of testosterone during the acquisition of the aversion has no effect on the rate of its extinction.

If the change in the behavior of the fluid-deprived male is due, as we have elsewhere proposed, to a deprivation-induced change in a testosterone-dependent mechanism, one would expect the temporal requirements for' fluid deprivation to correspond with the temporal requirements for testosterone deprivation. Thus, fluid deprivation should act upon the rate of extinction during extinction and not during acquisition. The present study was designed to determine if fluid deprivation in the adult male rat influences the rate of extinction by acting during the acquisition of the conditioned taste aversion or during its extinction.

\section{METHOD}

Twenty-four naive adult male Sprague-Dawley-derived rats were randomly assigned in equal numbers to one of four groups: fluid-deprived during acquisition and extinction (Group DD), nondeprived during acquisition and deprived during extinction (Group NDD), deprived during acquisition and nondeprived during extinction (Group DND), and nondeprived during acquisition and extinction (Group NDND). Following weaning and continuing until the beginning of the experiment, the animals were maintained on ad-lib food and water in same-sex colony cages with a $12: 12$ light/dark cycle (lights on at $0300 \mathrm{~h}$ ). On the first day of the experiment (Day 1), the animals were moved into individual cages, their weights were recorded, and those animals to be deprived during acquisition had their water bottles removed. Throughout the study, nondeprived rats always had access to water, either from their regular water bottles or from a graduated cylinder, while deprived animals only had access to water when a graduated cylinder was present. Also throughout the experiment, food was present ad lib and all animals were weighed just prior to the beginning of each daily dark cycle. 
On Days 2-7, after the lights went out, each animal was given a graduated cylinder of refrigerated water. The cylinder was removed $2 \mathrm{~h}$ later. On Day 8, the animals were all given access, for $2 \mathrm{~h}$, to two graduated cylinders, one containing chilled tap water and one containing chilled $10 \%$ sucrose solution $(\mathrm{w} / \mathrm{v}$ in water). At the end of the 2-h access period, the amount of sucrose solution consumed was recorded; each animal was injected immediately afterward with an illness-producing toxin $(.30-\mathrm{M} \mathrm{LiCl}, 20 \mathrm{ml} / \mathrm{kg})$, and the graduated cylinders were removed. On Days 9-10, each rat had access, at the beginning of the dark phase, to the chilled water for $2 \mathrm{~h}$.

The end of Day 10 marked the end of the acquisition phase of the experiment, and the deprivation/nondeprivation status of the DND and NDD animals changed accordingly. The animals continued to get the chilled water daily, at the beginning of the dark phase for 9 more days. Extinction testing began on the following day (Day 20) and continued for the rest of the experiment; all of the animals were given $2 \mathrm{~h}$ access to both the chilled tap water and the $10 \%$ sucrose solution each day after the light went off.

Daily testing of each animal continued until the criterion for extinction was reached, that is, a 1-day consumption of sucrose in an amount at least as great as the Day 8 (acquisition day) consumption. The number of extinction trials to reach that criterion was calculated for each animal; any rat that did not reach that criterion by 41 days of extinction was given a score of 42 .

\section{RESULTS AND DISCUSSION}

The data (number of extinction trials to criterion) were analyzed using a two-way analysis of variance. The deprivation state during the acquisition had no effect on rate of extinction $[F(1,20)=1.27]$, while the deprivation state during extinction did affect the rate of extinction $[\mathrm{F}(1,20)=47.55, \mathrm{p}<.001]$. There was no significant interaction $[F(1,20)=.33]$. The Student Newman-Keuls procedure $(\alpha=.05)$ indicated that Group DD and Group NDD formed a cluster of animals showing the fast, female-like extinction, while Groups DND and NDND formed a second cluster of animals showing the normal masculine, that is, slow, rate of extinction. See Figure 1.

The results clearly show that fluid deprivation increases the rate of extinction in male rats by acting upon some process that occurs during extinction. Deprivation during acquisition had no measurable effect on the rate of extinction. Thus, the results indicate a correspondence between the temporal requirements for fluid deprivation and the temporal requirements for testosterone deprivation. When males do not have testosterone during extinction, they extinguish rapidly; when males are fluid deprived during extinction, they extinguish rapidly. The absence of testosterone during acquisition has no effect on rate of extinction; the same is true for fluid deprivation. These results, along with the finding that the effects of deprivation in the male are blocked by daily injections of testosterone (Sengstake et al., 1978), offer support for the hypothesis that fluid deprivation affects a testosterone mechanism within the male, causing him to behave like a functional castrate.

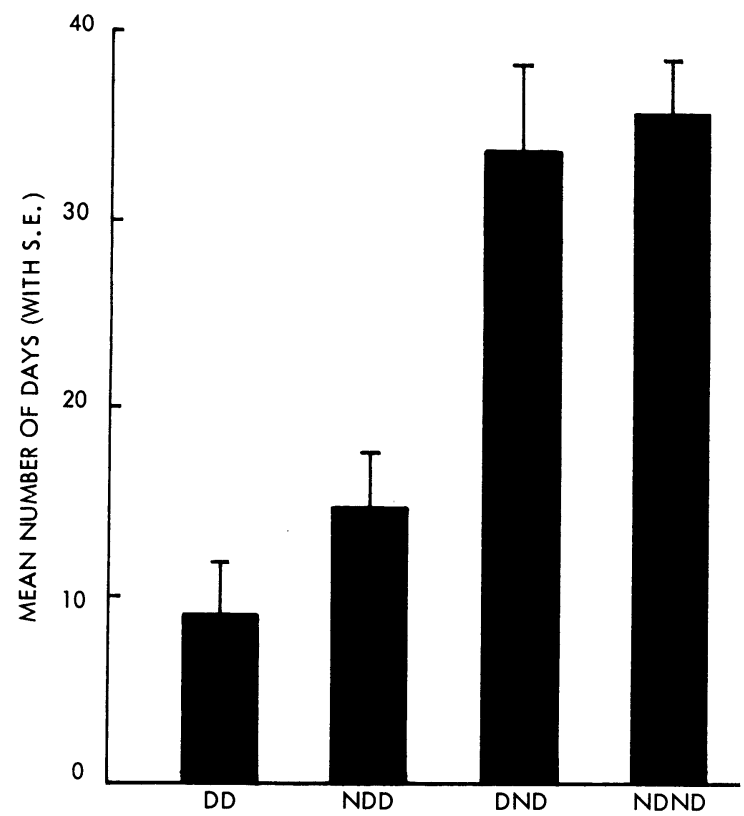

Figure 1. Mean $( \pm S E)$ number of days the animals deprived during acquisition and extinction (Group DD), the animals nondeprived during acquisition and deprived during extinction (Group NDD), the animals deprived during acquisition and nondeprived during extinction (Group DND), and the animals nondeprived during acquisition and extinction (Group NDND) drank less than $100 \%$ of their Day 1 consumptions.

There is also support for a more general statement of this hypothesis, namely, that specific experimental conditions alter specific behaviors by affecting testosteronedependent mechanisms. There are, for example, other experimental factors that affect both androgen levels and androgen-dependent behaviors. Prolonged food deprivation results in a decrease in serum testosterone (Howland \& Skinner, 1973) and a change in male sexual behavior in rats (Sachs, 1965); the same kinds of changes in sexual behavior are seen initially following castration (Davidson, 1966). Social isolation results in a marked reduction in plasma testosterone (Chambers \& Sengstake, 1978; Dessi-Fulgheri, Lupo di Prisco, \& Verdarelli, 1976), a reduction in aromatization of brain testosterone (Lupo di Prisco, Lucarini, \& Dessi-Fulgheri, 1978), a reduction in male sexual behavior (Gerall, Ward, \& Gerall, 1967; Gruendel \& Arnold, 1969), and a blocking of the slow rate of extinction of a conditioned taste aversion (Chambers \& Sengstake, 1978).

There seem to be, therefore, sufficient data to suggest that certain experimental factors affect certain behaviors by acting on testosterone-dependent mechanisms. The potential significance of such a hypothesis is a function of its generality. Since a variety of stressors have been shown to affect testosterone levels (see Martini \& Gonong, 1967), and since a number of behaviors, both reproductive and nonreproductive, are dependent on concurrent levels of testosterone (see Goy \& Goldfoot, 
1973), it would seem likely that mediation by a testosterone-dependent mechanism may well be an effective model for a variety of experimental effects on a variety of behaviors.

\section{REFERENCES}

Chambers, K. C. Hormonal influences on sexual dimorphism in the rate of extinction of a conditioned taste aversion in rats. Journal of Comparative and Physiological Psychology, 1976, 90, 851-856.

Chambers, K. C., \& Sengstake, C. B. Sexually dimorphic extinction of a conditioned taste aversion in rats. Animal Learning \& Behavior, 1976, 4, 181-185.

Chambers, K. C., \& Sengstake, C. B. The pseudo-castration effects of social isolation on extinction of a taste aversion. Physiology \& Behavior, 1978, 21, 29-32.

Chambers, K. C., \& Sengstake, C. B. Temporal aspects of the dependency of a dimorphic rate of extinction on testosterone. Physiology \& Behavior, 1979, 22, 53-56.

Davidson, J. M. Characteristics of sex behaviour in male rats following castration. Animal Behaviour, 1966, 14, 266-272.

Dessi-Fulgheri, F., Lupo di Prisco, C., \& Verdarelli, P. Effects of two kinds of social deprivation on testosterone and estradiol-17 $\beta$ plasma levels in the male rat. Experientia, 1976, 32, 114-115.

Gerall, H. D., Ward, I. L., \& Gerall, A. A. Disruption of male rat's sexual behaviour induced by social isolation. Animal Behaviour, 1967, 15, 54-58.
Goy, R. W., \& Goldfoot, D. A. Hormonal influences on sexually dimorphic behavior. In R. V. Green \& E. B. Astwood (Eds.), Handbook of physiology: Endocrinology (Sec. 7, Vol. 2, Pt. 1). Washington, D.C: American Physiological Society, 1973. Greundel, A. D., \& Arnold, W. J. Effects of early social deprivation on reproductive behavior of male rats. Journal of Comparative and Physiological Psychology, 1969, 67, 123-128.

Howland, B. E., \& Skinner, K. R. Effects of starvation on gonadotropin secretion in intact and castrated male rats. Canadian Journal of Physiology and Pharmacology, 1973, 51, 759-762.

Lupo di Prisco, C., Lucarini, N., \& Dessi-Fulgheri, F. Testosterone aromatization in rat brain is modulated by social environment. Physiology \& Behavior, 1978, 20, 345-348.

Martini, L., \& Ganong, W. F. (EDs.). The psychology of learning and motivation: Advances in research and theory IV. New York: Academic Press, 1967.

SACHS, B. D. Sexual behavior of male rats after one or nine days without food. Journal of Comparative and Physiological Psychology, 1965, 60, 144-146.

Sengstake, C. B., Chambers, K. C., \& Thrower, J. H. The interactive effects of fluid deprivation and testosterone on the expression of a sexually dimorphic conditioned taste aversion. Journal of Comparative and Physiological Psychology, 1978, 92, 1150-1155.

Received for publication May 3, 1979. 